\title{
EDUCATIONAL INTERACTION OF THE STUDENTS WITH BEHAVIORAL DISORDERS IN THE CONTEXT OF TRANSFORMATION OF EDUCATIONAL PARADIGMS: THE CASE OF AN EDUCATIONAL CENTRE
}

\author{
Alvyra Galkiene \\ Ieva Kulakauskienè \\ Lithuanian University of Educational Sciences, Lithuania
}

\begin{abstract}
The article analyses the manifestation of educational interaction among fourteeneighteen - year - old students with behavioral disorders that are being educated in the socialization centre. The method of a structured interview has been applied in order to determine the peculiarities of such interaction in the contexts of the traditional and the progressive education, prioritizing the culture of cooperative learning culture as a prerequisite for fostering social relations and learning a proper social behaviour. The discourse of the students, teachers and providers of special educational assistance has been analyzed in the context of the lesson organization, cooperation activities and surmounting impediments. The study results revealed that feelings of dignity and belonging to the community are of particular importance for the students of the social centre. However, the education here is based more on the teaching than on the learning strategy, as well as on a vertical interaction between teachers and students. Progressive education episodes, flexible organization of education and joyous atmosphere during the lessons establish a horizontal relationship and reduce tension in the educational environment.
\end{abstract}

Keywords: behavioral disorders, educational interaction progressive education, traditional education.

\section{Introduction}

The educational system is one of the key factors in the development of a society. The society that is developing its own future on the basis of democratic values, seeks equal participation of all its members in the life processes. The opportunities to achieve the educational objectives of a democratic society can be opened by educational systems that are based on the ideas of progressivism. Such education systems emphasize democratic ideals, respect for the student, goal - oriented activities and active cooperation with the community (Hayes, 2006, Goossens \& Van Gorp, 2016). In order to transform the unified education 
system into a free and based on the ideals of democracy one, we have to overcome prioritization of the system based on abstract knowledge and to switch to the development of personal autonomy and social cooperation. (Duobliene, 2010, Bitinas, 2013). Access to different educational systems is fundamentally modifying the educational goals, their methods of implementation and evaluation of the results (McManus, 2001). It is important that a change in overall education system is necessary when seeking to implement changes in education. The anticipated result cannot be achieved having internalized only one of the components of an education system that is being updated (Fullan \& Miles, 1992).

After the restoration of independence in Lithuania, from the year 1991, significant changes in the educational system for the students with special educational needs have been made. In 1991, when Law on Education of the Republic of Lithuania validated the opportunity for all the students with disabilities or special educational needs to study at general education institutions, the majority of them moved from special education institutions to general education schools. Only students with severe and profound special educational needs remained at special purpose educational schools. Six special purpose educational schools, "Socialization centres", are designated for the students with severe behavioral problems. Their mission is to implement an average child - care tool for adolescents aged 14 to 18 years in cases provided by the Criminal Code of the Republic of Lithuania. Behavioral disorders are among top of the most disruptive disorders for social and educational ties. Students who have this disorder, face challenges not only when being trained interpersonal skills, but experience academic difficulties when learning (Watt et al., 2014). Public attitudes often marginalize people with this disorder, and possible success forecasts are unreliable (McGuire, 2015). Behavioral disorder restricts the pupils' success at a general education institution by several aspects: limitation of social ties with peers and teachers, self - regulation problems and academic difficulties (Simpson, 2004). However, significant results can be achieved with the help of purposeful application of the target - oriented education. Systematic exercises, raising self-regulation skills, appropriate peer interaction skills, emotional regulation skills, and conflict resolution strategies, determine significant progress of such students (Zeng et al., 2016). Research shows that external support enhances educational interaction and increases the opportunities for inclusion of such students. Collaborative problem-solving is highly recommended, as it increases students' social validity (Simpson, 2004). Creation of a favourable, goal-oriented educational environment and continual assessment of its effectiveness also have significant importance on the expected development of the student's behaviour (O'Shaughnessy et al., 2003). 
Research question. How do the components of educational paradigms reflect themselves in the educational interaction of the students with behavioral disorders?

Research methodology. Assuming the metamorphosis of the paradigms of an educational system based on traditionalism ideas into the educational system based on the ideas of progressivism, an educational interaction in a socially sensitive educational environment, a socialization centre, is analysed. Order, hierarchy and cultural transference prevail in an education system based on traditionalism ideas, whereas the ideas of progressivism actualize personal development and social co-operation (Duobliene, 2010). These educational systems are revealed by different educational approaches. Traditional education is based on an educational training strategy which emphasizes a vertical cognitive teacher's relationship with a student. Meanwhile, ideas of progressivism actualize a learning strategy, which focuses on collaborative teacher-pupil relationship (McManus, 2001). In this way, educational interaction mechanisms switch from the direct knowledge transmission system to the collaborative educational system where the impact power is distributed among the participants of the educational reality (Juceviciene et al., 2010). Successful learning is achieved through cooperation, primarily in the social level through interpersonal interaction means and sharing a common learning experience (Vizgirdaite \& Juceviciene, 2014).

McManus (2001), referring to Smith \& Waller (1997), provides characteristics of teaching and learning approaches (Table 1).

Table 1 Characteristics of teaching and learning approaches

\begin{tabular}{|l|l|}
\hline $\begin{array}{l}\text { Characteristics of Teaching - Centered } \\
\text { Groups }\end{array}$ & $\begin{array}{l}\text { Characteristics of Learning - Centered } \\
\text { Groups }\end{array}$ \\
\hline Individual accountability only & $\begin{array}{l}\text { Both group and individual accountability. } \\
\text { Members keep themselves and others } \\
\text { accountable for high quality work }\end{array}$ \\
\hline Little or no attention to group formation & Deliberately formed groups \\
\hline $\begin{array}{l}\text { Assignments are discussed with little } \\
\text { commitment to each other's learning }\end{array}$ & $\begin{array}{l}\text { Members promote each other's success, } \\
\text { doing real work together }\end{array}$ \\
\hline $\begin{array}{l}\text { Teamwork skills are ignored. Leader is } \\
\text { appointed to direct members' participation }\end{array}$ & $\begin{array}{l}\text { Teamwork skills are emphasized. Members } \\
\text { are taught and expected to use collaborative } \\
\text { skills }\end{array}$ \\
\hline $\begin{array}{l}\text { No group processing of the quality of the } \\
\text { groups work }\end{array}$ & $\begin{array}{l}\text { Group process the quality of work and how } \\
\text { effectively members are working together }\end{array}$ \\
\hline
\end{tabular}

McManus (2001), referring to Smith \& Waller (1997)

These characteristics reveal the differences of the teaching and the learning strategies in the aspect of cooperation. Taking into account the fact that 
interpersonal interaction is the most affected part of the educational system of students with behavioral disorders, our survey statistics are analyzed in accordance with McManus' (2001) construct of teaching and learning characteristics.

Research participants. The research was carried out in one of the Lithuanian socialization centers. Six male trainees of this centre, aged $16-17$, agreed to participate in the study. The average time of the adolescents who took part in the study of the education at the socialization center is 4 months. Also, four of the teachers of the boys and two special educators participated in the research.

Research organization. The data were collected using the method of a structured interview. Individual discussions were held with each interviewee, based on a prearranged interview plan. In order to increase the credibility of the research results, a group of respondents was formed from a variety of the participants of the educational reality - students, teachers and student assistance specialists. The method of structuring content analysis is applied for the analysis of qualitative data.

Research ethics. Determination of the participants to participate in the research was voluntary. Confidentiality of educational institutions and research participants has been preserved, without indicating either the name of the institution, or the names of the participants. Coding of the focus group: (S) student; (T) - teacher; (SAS) - student assistance specialist.

Research limitations. The research was carried out in one specific educational institution, so the results cannot be generalized in respect of all the learners with behavioral disorders. It reveals possible trends and encourages further studies of individuals with behavioral disorders.

\section{The research data analysis}

Feeling of the participants of the educational reality. Interpersonal interaction expression results are primarily reflected by the participants' wellbeing in the community. The research results show that the students of the socialization centre, the research participants, feel well enough in this community. The most important aspects that students distinguished when talking about their well-being are: 1) dignity intact "... I'm not insulted or humiliated by friends "(S), "I am not isolated from other students" (S);2) meeting the need of belonging to the community "I am not marginalized by friends" (S), "I get on well with friends" (S), "I get along well with teachers" (S). However, the students recognize the fragility of this interaction and the need to remain within the limits "...when you gossip too much, other peers may hit you on your head" (S). Interpersonal relationships between students in this environment are created 
on the basis of common interests and internal motivation to communicate. They are hardly affected by external requirements. In most cases, the frontiers in this relationship are drawn by the students themselves, so the need for human dignity and belonging to someone is satisfied.

The teachers' relationships with the students are influenced by external requirements to change the behaviour of the students and to achieve certain academic results. It is interesting that the teachers put the greatest emphasis on the processes that take place in the classroom during the research. The teachers' feeling during the lessons is twofold and has to be related to the elements of the educational paradigm a teacher uses in his work. Teachers who create learning environments feel well in the interaction with the students "I feel at ease during my classes and I enable my students feel this way" (T), "Our lessons are always accompanied by laughter and fun" (T). It is obvious that the correlation created by horizontal relationships allows both students and teachers feel unembarrassed. The feeling of tension in the educators' discourse occurs when a vertical educational relationship with students is planned. In this case, the situation can be resolved by flexibility and ability to adapt to the needs of learners "You often have to improvise as you come prepared to the lesson and you see that what you had planned is going to fail; something needs to be changed; you always try to get the students interested, because it is not possible to force them to learn" (T). The situation becomes complicated when elements of the teaching strategy prevail in the educational interaction "everything usually depends on the lesson theme" (T), "sometimes the topic is not interesting" (T). Academic purposefulness (characteristic of traditional education), hinders transferring of the content of the subject into the context of actual reality and analyzing it in connection with the experience that is close to the student's heart, thus creating a horizontal educational interaction. The research results show that the teacher's well - being in the interaction with these students is significantly influenced by the factor of overall mood of the students in the classroom "everything usually depends on the mood of the students in the classroom" (T). Human mood is influenced by numerous factors. It may reflect the events of the past and may not be associated with a particular present situation, but it has an impact on the present situation, on the other hand, it can be affected by current events, and vary. Educational strategy selected by the educator can affect students' mood and influence the educational process. Summing up the students and teachers' well - being in the educational interaction, a relation between the selected strategy of training and students and teachers' well-being can be detected (Fig. 1). 


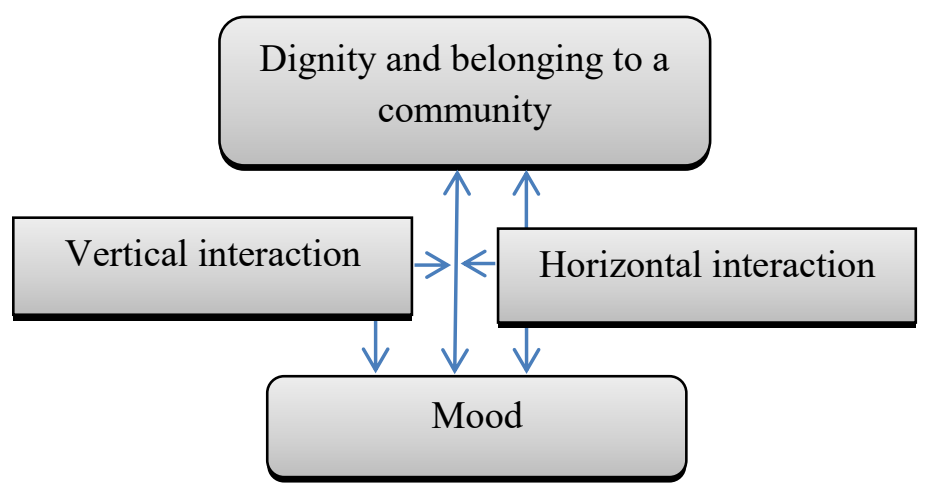

Figure 1 Factors influencing well - being of the educational participants in the pedagogical interaction

The research results show that the recognition of their dignity and the sense of belonging to the community are essential for students with behavioral disorders. Educational strategy selected by the educator determines a horizontal or a vertical relationship with the students. In case of the teaching strategy, the teacher creates a vertical educational relationship. In this case, the students' mood will depend on two components; newsworthiness of the proposed training material and the student's learning performance. In case of success the student's mood will be elevated, the feeling of dignity will be supported. It is understandable that the feeling in the teacher - student interaction will be good. In case of failure, the student's mood will be bad, and feelings of dignity and belonging to the community will become vulnerable. Volatility of stress in educational interaction will be felt. This conclusion can be supported by the teachers' statements: "The atmosphere is very diverse, everything mostly depends on students' mood and lesson theme" (T). Meanwhile, when creating a horizontal interaction which is an element of the learning strategy, and responding to the students' need to have dignity intact and the sense of belonging to the community, the students' good mood is supported, and, thereby, well - being of all the participants of the educational reality. Thus, a reasonable question arises: "Which education organization components enable you to create a horizontal interaction of education participants?"

Lesson organization. The research findings show that teachers, when organizing lessons, apply methods attributable to the traditional teaching strategy: "explanation" (T), "narration, only I try to make it shorter" (T), "example demonstration" (T), practical assignments, self studying, etc. Application of these methods determines a vertical educational interaction. Collaborative techniques assist the creation of a horizontal interaction. Students that took part in the research indicate only one method that generates cooperation relations, i.e., teamwork "we work in groups" (S), "Some teachers 
organize group work sessions" (S). This method was mentioned by half of the students involved in the research and this presupposes that it has been applied only episodically "we have worked in a group with other friends, but this happens very rarely" (S). It is understandable that application of cooperation fostering techniques in a group of students with behavioral disorders requires a particular organization and is not always possible "some teachers organize group work sessions, but do not take part" (S). It is much easier to organize individual work of these students "...all the learning is independent" (S) say students. Teachers adapt the assignments for the students with respect to their needs and abilities "sometimes it happens so that I select different tasks for nearly all the students in the classroom according to their capabilities" (T). Most commonly, the assignments are prepared individually for each student, but sometimes, when the students' capabilities are comparable, the assignments are prepared for separate groups of the students. "If it is possible, I tailor the content of the lesson to several groups of the students according to their abilities and prepare tasks according to it" (T). However, an individual organization of work does not create a horizontal educational interaction, but consolidates the individuality not only in learning, but also in the wider social context "I get additional tasks that I do independently and alone" (S). Pupils' statements prove that individual activities do not encourage motivation to learn either "I get individual tasks designated especially for me, but I do not do them" (S). Moreover, too immoderate individualization of the activities in a socially sensitive environment provokes greater tension in interpersonal relations. Individual teacher's relationship with a student with behavioral disorder is a very important sign that consolidates his relationship of belonging to the community. However, from the perspective of the community, it is very important that this relationship would be balanced and would not cause others such feelings as exclusion and lack of such relationships "I don't get any individual tasks" (S), "I don't get anything" (S).

Cooperation culture. The research results reveal a more developed culture of individual work than that of cooperation among teachers. A significant aspect of communication between students' teachers is one of the components of cooperation. Teachers note that the issues of the efforts of the students' learning and their behaviour are discussed with all of their teachers "we talk about the behavior, speech, performance in certain subjects, how the pupil adapts or does not adapt, how he feels in class and in the surrounding environment and among other students" (T), "...with each other, with other subject teachers very often..." (T). However, this communication does not develop into overall activities designed develop students' communication culture, specifically targeted to develop their interpersonal relationships. Individual activities also dominate in the group of specialists for assistance to students "Self-awareness programme 
for children with special educational needs is being conducted, but it is more like individual counseling, according to an individual scheme" (SAS). A pronounced separation of functions between the teachers and student assistance specialists has been observed "Unfortunately, we communicate on these issues very rarely" (SAS). This way, the specialists' team acquires a negative connotation of problem solvers among students. If you turn to a specialist, it means that you publicly acknowledge your problems. Therefore, students tend to avoid meetings with them "I know that the school has such specialists as psychologist, social educator, but I do not communicate with them because I don't like them" (S). This is not always the case. Some of the students trust the professionals and make use of their assistance "when I have problems, I turn to a psychologist or a social educator and get the assistance from them that I need" (S). However, these are more solitary cases.

Difficulty coping strategies. Research results show that students' with behavioral disorders difficulty coping mechanism in this educational institution is more associated with incentive system of the students "I often receive incentives" (S), "...every lesson" (S). Most commonly, the students are encouraged by a good mark or praise "nobody evaluates badly, they give remarks for me to react to them; they do not say that you are unable to do something, do not humiliate in front of the others" (S). When evaluating students, teachers try to form an adequate ratio of the efforts made and the results "your evaluation, the mark, depends on how well you perform. When you work little, you get little, and when you work normally and you try, the evaluation is also good" (S). However, maintaining the balance between the requirements and the result in this environment is a complex task "If the teachers begin to demand too much from me, I call them names, then the teachers write official reports on me" (S). Performance evaluation is important for the students "good marks and evaluations are also important, but only because they affect vacations" (S). Status in the community is very important for the students, which is also developed by the feedback on their performance "teachers' incentives are of importance" (S), "friends' opinion about me is important" ( $\mathrm{T})$.

The expected success denial signs are pronounced in the students' discourse as well. They can be seen as defensive postures, avoiding a possible failure "...I don't try to learn, I don't learn, I just sit in class and that's it; I tell the teacher to give me a four and that's it" (S), "Recognition of classmates or teachers' opinion about me are not important" (S). Meanwhile, teachers tend to support these students, foster their self-esteem and develop self-confidence as much as possible. Attitudes of sympathy are prominent in the teachers' discourse "We teach these children, with a very good will, you can do nothing about them, we all make mistakes and it requires patience to teach such 
children" (T). This attitude helps the teacher to mobilize himself and shape tolerance when raising requirements "I can see that at least he does a minimum during my classes and I give a positive mark" (T). This attitude encourages providing assistance, responding to the needs and supports self-confidence "I try to support them, once again demonstrating tasks and so on. I try to ensure that pupils do not suffer from frustration" (T).

The research results indicate that the difficulty coping mechanisms, when educating students with behavioral disorders, on the one hand reflect each student - oriented relationship, but on the other hand, the vertical educational interaction takes place which does not unite for consolidated purpose or search for common solutions. The elements characteristic of the traditional educational paradigm are very much pronounced in this educational system.

\section{Discussion and conclusions}

When responding to the research question: "How do educational paradigm transformation components reflect in the educational interaction of the students with behavioral disorders?" it is worth emphasizing the teaching and the learning strategies, as presuming, respectively, the traditional and the progressive educational paradigms. Expression of the teaching and the learning strategies in the educational process is revealed through cooperation component (McManus, 2001) of students with behavioral disorders, which manifest in constant difficulties when cooperating with people and the environment, due to lack of capacity to manage conflict situations, understand their own behaviour and other people's feelings and intentions (Pukinskaite, 2008).

Learning strategy based on the culture of cooperation prioritizes learners' overall activities, and, at the same time, personal and shared responsibility and success experiences. Students with behavioral disorders due to a lack of internal impulse control can hardly restrain their emotions, feelings, and adapt in the society. External control is especially important for them (Kalpokiene \& Gudaite, 2007). A cooperating group when seeking the overall success reinforces the external control with respect of each other and supports group balance. Our research results show that, when applying the teaching strategy and focusing on individual tasks, a student individually experiences success and failure situations. In order not to suffer a possible failure, no opportunity remains to share responsibility, therefore, avoidance strategy is chosen and activities are ignored. Basing education organization on the learning strategy, cooperating groups are purposefully formed to carry out various activities and to solve problems. Our research results show that the teachers work cooperatively to discuss their students' educational performance and progress. Specialists organize a target group for students' deeper self - awareness. However, other 
authors' experience shows that pupils with behavioral disorders gain experience of functioning in the society by participating in group activities, which simulate social situations. Students participating in activities of such groups learn experience from recognizing social characters and their correct interpretation to an appropriate choice of response to social challenges (Mitchell, 2014). Education organization focused on the individual impact hinders the organization of similar activities. The results of this research indicate that specialist assistance has a connotation of a possibility of difficulty solving and evokes denial of meeting with such specialists. Meanwhile, each community member's success and strength prioritized in a collaborative culture emphasizes the performance goals for achieving the common good. The phenomenon of help becomes a natural part of common activities that helps not only to deal with social problems, but also to learn to live without them. Our research results confirmed the observation of Visser \& Rayner (1999) that flexibility and a good mood when educating students with behavioral disorders not only reduce the number of unwanted behavior episodes, but they help to overcome even the occurrences of aggression.

\section{Conclusions}

The results of this research revealed that the educational system of adolescents with behavioral disorders at the center of socialization is based on the traditional educational strategy. Educational interaction is dual, it takes place between a teacher and a student, and individual students' activities dominate. Students and teachers' cooperation has not been developed and it hinders learning to master a variety of social situations, to establish more flexible mutual relations, and to focus on the creation of the common good. Teachers are creating a sensitive relationship with the students in order to understand their situation and to respond to their needs. Although a sensitive teacher's relationship reinforces individual relationship, a faster reorganization of the whole educational system into education strategy based on the creation of a progressive social capital would help speed up to achieve the results of the mission of this centre.

\section{References}

Ališauskas, A., \& Šimkienė, G. (2013). Mokytojų patirtys, ugdant mokinius, turinčius elgesio ir (ar) emocijų problemų. Specialusis ugdymas, (1), 51-61.

Bitinas, B. (2013). Rinktiniai edukologiniai raštai, I T. Vilnius: Edukologija.

Duoblienè, L. (2010). Švietimo politika ir globalizacija: nacionaliniai ir supranacionaliniai ypatumai. Acta Pedagogica Vilnensia, (25), 69-84. 
Fullan, M. G., \& Miles, M. B. (1992). Getting reform right: What works and what doesn't. Phi delta kappan, 73(10), 745-752.

Goossens, C., \& Van Gorp, A. (2016). The myth of The Phoenix: progressive education, migration and the shaping of the welfare state, 1985-2015. Paedagogica Historica, $52(5), 467-484$.

Hayes, W. (2006). The Progressive Education Movement: Is it Still a Factor in Today's Schools?. Rowman \& Littlefield Education. 15200 NBN Way, PO Box 191, Blue Ridge Summit, PA 17214-0191.

Jucevičienè, P., Gudaitytė, D., Karenauskaitė, V., Lipinskienė, D., Stanikūnienė, B., \& Tautkevičienè, G. (2010). Universiteto edukacinė galia: atsakas 21-ojo amžiaus iššūkiams: monografija. Kaunas: Technologija.

Kalpokienė, V., \& Gudaite, G. (2007). Elgesio sutrikimų turinčių paauglių Ego funkcijos ir jų ryšys su įveikos strategijomis. Psychology, 35, $42-54$.

McGuire, N. M. (2015). Environmental Education and Behavioral Change: An Identity-Based Environmental Education Model. International Journal of Environmental and Science Education, 10(5), 695-715.

McManus, D. A. (2001). The two paradigms of education and the peer review of teaching. Journal of Geoscience Education, 49(5), 423-434.

Mitchell, D. (2014). What really works in special and inclusive education: Using evidencebased teaching strategies. Routledge.

O'Shaughnessy, T. E., Lane, K. L., Gresham, F. M., \& Beebe-Frankenberger, M. E. (2003). Children placed at risk for learning and behavioral difficulties: Implementing a schoolwide system of early identification and intervention. Remedial and Special Education, 24(1), 27-35.

Pukinskaitè, R. (2008). Eksternalių elgesio sunkumų turinčių vaikų ịtaka šeimai. Medicina, 38(4), 431-438.

Simpson, R. L. (2004). Inclusion of students with behavior disorders in general education settings: Research and measurement issues. Behavioral Disorders, 19-31.

Simpson, R. L. (2004). Inclusion of students with behavior disorders in general education settings: Research and measurement issues. Behavioral Disorders, 19-31.

Visser, J., \& Rayner, S. (Eds.). (1999). Emotional and Behavioural Difficulties: A Reader. QEd.

Vizgirdaite, J., \& Juceviciene, P. (2014). Designing and Implementing a Didactic System as an Educational Empowerment of Student Collaborative Learning in the University Studies. Procedia-Social and Behavioral Sciences, 116, 3830-3837.

Watt, S. J., Therrien, W. J., \& Kaldenberg, E. R. (2014). Meeting the Diverse Needs of Students with EBD in Inclusive Science Classrooms. Beyond Behavior, 23(2), 14-19.

Zeng, S., Benner, G. J., \& Silva, R. M. (2016). Effects of a Summer Learning Program for Students at Risk for Emotional and Behavioral Disorders. Education and Treatment of Children, 39(4), 593-615. 